\title{
The Big Five Personality Traits and Narcissism as the Predictors of Anxiety and Confidence before Archery Class Final Exam
}

\author{
Nihal Dal \\ Faculty of Sport Sciences, Manisa Celal Bayar University, Turkey
}

Copyright $(2018$ by authors, all rights reserved. Authors agree that this article remains permanently open access under the terms of the Creative Commons Attribution License 4.0 International License

\begin{abstract}
In the present study I investigated whether the big five personality traits together with narcissism may have ability to predict the anxiety and self-confidence in physical education teacher candidates immediately before archery course final exam. The sample consisted of 52 college student athletes ranging in age from 20 to 24 . Participants first completed the measures of the Big Five personality traits and narcissism measures. Then, their anxiety and self-confidence levels were measured via 100 $\mathrm{mm}$ visual analogue (VAS) scale immediately before the archery practical final exam. Results indicated that among the Big Five personality traits only agreeableness and openness to experience was positively correlated to anxiety. On the other hand, narcissism was negatively correlated to anxiety and positively correlated to self-confidence. In two regression analyses in a stepwise fashion, it was tested whether the model consisting of the Big Five personality traits and narcissistic personality trait may have ability to predict pre-exam anxiety and self-confidence. Results of the regression analysis demonstrated that final model containing solely narcissism may explain significant amount of variation in both anxiety and self-confidence. Overall, findings observed in the present study indicated that teacher candidates high on narcissism may have lower level of anxiety and higher level of self-confidence before a practical academic examination.
\end{abstract}

Keywords The Big Five Personality Traits, Narcissism, Anxiety, Self-confidence, Archery

\section{The Big Five Personality Traits and Narcissism as the Predictors of Anxiety and Confidence before Archery Class Final Exam}

During their college education period physical education teacher candidates repeatedly face a good deal of practical course exam which requires both physical and mental abilities. As these exams may have vital effect of students' academic achievement, students may experience intense anxiety and other negative emotional experiences. Most of the previous studies investigating psychological (or emotional) responses before an academic examination focused largely on theoretical courses such as mathematic (Chapell et al., 2005; Ma and Xu, 2004) or second language learning (MacIntyre and Gardner, 1989). However, in several scientific disciplines, including sport sciences, academic success is not determined only by means of theoretical courses. Practical courses, which require considerable amount of physical and mental effort also play a vital role in academic success of physical education teacher candidates. Therefore, it is of great importance to examine factors that can possibly influence students' psychological responses in a practical examination.

Test anxiety, which is defined as a variable referring to enduring differences in the tendency to become anxious in situations where one's performance will be judged or evaluated (Dacanay, 2016, p. 554) is a relatively well-known trait-like variable. Although test anxiety has been demonstrated to effect on academic achievement, less is known regarding the predictors of test anxiety, especially in practical academic tests. In the present study, based on the argument by Dacanay (2016) suggesting that personality may influence the way stressful events, are perceived and appraised. I decided to recognize the Big Five personality traits together with narcissistic personality trait as the possible antecedents of academic test anxiety and confidence immediately before a practical academic test (archery course final exam), which requires considerable amount of physical and mental effort.

Among the personality traits within the Big Five model neuroticism and conscientiousness are the most important candidates that can possibly be associated with academic test anxiety. Previous research consistently revealed a 
moderate relationship between anxiety and neuroticism within the Big Five personality model. As the neuroticism is associated with the arousability of the limbic system (Eysenck, 1967) and imbalance of the autonomic nervous system (Eysenck, 1982, p. 13) it is quite logical to expect that neuroticism may give rise to higher level of anxiety and lower level of confidence in stressful situations such as academic tests. Conscientiousness is another Big Five facet that can be associated with emotional responses before an academic test. Previous research provided strong support for the usefulness of conscientiousness in diverse academic settings. For example, Tok, and Morali (2009) found conscientiousness to be associated with academic success in physical education candidates. Further, Dacanay, (2016) demonstrated that conscientiousness is negatively correlated to test anxiety in college students. However, no previous study provided evidence for association among conscientiousness, anxiety and confidence before a practical academic exam.

The last personality trait that is considered as the possible predictor of academic test anxiety and confidence is the subclinical "normal" narcissism. Before presenting the features of narcissistic personality, it would be necessary to make a distinction between two kinds of narcissism. Previous research provided strong empirical support for the two types of narcissism, namely grandiose versus vulnerable narcissism (Cain, Pincus, and Ansell, 2008; Miller et al., 2011). In the present study, I focused on grandiose or sub-clinical type of narcissism as the predictor of academic test anxiety and confidence. Narcissism is characterized by the feeling of superiority, exaggerated self-importance, self-sufficiency, grandiosity and vanity, entitlement and exploitation, and dominance and authority (Jonkmann, Becker, Marsh, Lüdtke, and Trautwein, 2012, p. 738). For example, in a study by Gabriel, Critelli, and Ee, (1994) despite the lack of correlation between actual intelligence and narcissism, self-rated intelligence moderately correlated to narcissism. Likewise, Farwell and Wohlwend-Lloyd (1998) found narcissism to be positively associated with self-estimated final grade. Taken together, it seems that individuals high on narcissism may have lower level of anxiety and higher level of self-confidence before an important academic test due to their vulnerability to use self-enhancement strategies.

In the present study, I aimed to examine whether students' anxiety and self-confidence level during a practical archery final exam may be predicted by the Big Five personality traits and narcissistic personality trait. In the light of aforementioned theoretical reasons and research findings, I predicted that among the Big Five personality dimensions, conscientiousness should be negatively correlated to anxiety and positively correlated to self-confidence. Inversely, I expected to find neuroticism to be positively associated with anxiety and negatively associated with self-confidence. Lastly, I hypothesized that narcissistic personality buffers anxiety and enhances self-confidence.

\section{Method}

\subsection{Participants}

The sample consisted of 52 physical education teacher candidates (13 females) ranging in age from 20 to 24 , [mean 21.4 (2.16)]. All participants were recruited from the Faculty of Sports Sciences. Participants were required to abstain from the use of any medications or commercial ergogenic aids that could influence athletic performance. All experimental procedures were approved by the local ethics committee, and all data were collected in accordance with the latest version of the Helsinki Declaration. All participants completed a form providing informed consent, as approved by the ethics committee.

\subsection{Personality Measures}

The Short Form of the Five-Factor Personality Inventory developed by Tatar (2005) was used to measure the Big Five personality traits; this is an 85 -item personality inventory designed to evaluate the five main personality traits, namely neuroticism, extraversion, openness to experience, agreeableness, and conscientiousness. Item responses are made using a 5-point scale. In this study, only the conscientiousness subscale of the five-factor personality inventory was used.

\subsection{Narcissism}

Narcissism was measured through the use of the short version of the Narcissistic Personality Inventory (NPI-16) developed by Ames, Rose, and Anderson (2006). The NPI-16 is a 16-item forced choice measure: one narcissistic and other non-narcissistic. Narcissistic responses are summed to calculate an overall narcissistic personality score. The NPI-16 was translated into Turkish by Atay (2009).

\subsection{Anxiety and Self-confidence}

In order to measure pre-exam anxiety and self-confidence $100 \mathrm{~mm}$ Visual Analogue Scale (VAS) was used. VAS marked at one end as "very low anxiety / self-confidence" and at the other as "very high anxiety / self-confidence". Participants were instructed to rate their anxiety and self-confidence level immediately before the exam. Individuals rate their pre-exam anxiety and self-confidence on two different VASs (one for anxiety and one for self-confidence).

\subsection{Procedure}

Participants first completed measures regarding the Big Five personality traits and narcissism. Afterwards, participants were allowed to make 10 shots for warm up 
and to adjust the bow's site. Then, participants were instructed to make 10 shots from $18 \mathrm{~m}$ to an $80-\mathrm{cm}$ diameter target. The shooting task was self-paced, so participants decided when to shoot an arrow and how long to prepare to shoot. Participants were also told that they had to get at least 60 points in order to be receive the course credits.

\subsection{Statistical Analysis}

To analyze obtained data, I first calculated Pearson correlation coefficient among the Big Five personality traits, narcissism and pre-exam anxiety and self-confidence. Afterwards, linear regression analyzes in a stepwise fashion were conducted to explore whether regression model consisting of the Big Five personality traits and narcissism may have ability to predict variation in pre-exam anxiety and self-confidence.

\section{Results}

Results of the Pearson correlation coefficient demonstrated that among the Big Five personality traits only openness to experience $(\mathrm{r}=.39, \mathrm{p}=.010)$ and agreeableness was positively and significantly correlated to pre-exam anxiety. On the other hand, narcissism was significantly correlated to both pre-exam anxiety and self-confidence. Hence, narcissism was negatively associated with pre-exam anxiety $(-.41, \mathrm{p}=.006)$ and positively associated with pre-exam self-confidence $(-.31$, $\mathrm{p}=.044)$

Based on the significant relation of personality traits to anxiety and self-confidence, I decided to perform two regression analyzes in a stepwise fashion to test whether regression model consisting of the Big Five personality traits together with narcissism may have account for the variation in pre-shooting anxiety and self-confidence. As can be shown in Table 2 and 3 , results of regression analyzes indicated that a final model containing solely narcissism was able to explain significant amount of variance in both pre-exam anxiety and self-confidence.

\section{Discussion}

In the present study, it was aimed to examine whether the Big Five personality traits together with narcissism may be associated with pre-exam anxiety and self-confidence measured immediately before an archery practical final exam in physical education teacher candidates. The results observed in the present study provided partial support for my prediction regarding the association among personality, anxiety and self-confidence. Therefore, among the personality traits considered in this study, narcissism emerged as the strongest psychological construct with a potential to predict physical education teacher candidates' pre-exam anxiety and self-confidence immediately before archery class final exam. On the other hand, neither conscientiousness nor neuroticism has been found to be associated with pre-exam anxiety and self-confidence.

Table 1. The relation of the Big Personality traits and narcissism to anxiety and self-confidence

\begin{tabular}{ccccccc}
\hline & Extraversion & Agreeableness & Conscientiousness & Neuroticism & Openness & Narcissism \\
\hline Confidence & .232 & -.079 & .237 & -.195 & -.047 & $.308^{*}$ \\
\hline Anxiety & -.122 & $.339^{*}$ & .114 & .106 & $.389^{* *}$ & $-.413^{* *}$ \\
\hline${ }^{*}<.05 \quad * * \mathrm{p}<.01$ & & & & & &
\end{tabular}

Table 2. Ability of the Big Five personality traits and narcissism to explain self-confidence

\begin{tabular}{cccccc}
\hline & $\mathrm{B}$ & $\mathrm{Beta}$ & $\mathrm{t}$ & $\mathrm{R}$ & $\mathrm{R}_{\text {adj }}^{2}$ \\
\hline Constant & 6.51 & & & .33 \\
Narcissism & .201 & .091 & 12.07 & .09 \\
\hline
\end{tabular}

Table 3. Ability of the Big Five personality traits and narcissism to explain anxiety

\begin{tabular}{cccccc}
\hline & $\mathrm{B}$ & $\mathrm{B}$ eta & $\mathrm{t}$ & $\mathrm{R}$ & $\mathrm{R}_{\text {adj }}^{2}$ \\
\hline Constant & 4.74 & & 7.90 & & .432 \\
\hline Narcissism & -.310 & .101 & -3.06 & .43 \\
\hline
\end{tabular}


The most notable finding of the study was the association of narcissistic personality to anxiety and self-confidence. In this respect, narcissistic personality appeared as psychological factor that buffers anxiety and enhances self-confidence immediately before a practical academic exam. The underlying reason for the relation of narcissism to low anxiety and high confidence concerns the self-concept of individuals high on narcissistic personality trait. Hence, previous research has consistently indicated that individuals high on this trait may have exaggerated or inflated beliefs regarding their capabilities (Jonkmann et al., 2012; Robins and Beer, 2001). In this respect, individuals high on narcissism may possibly perceived themselves more capable to be successful which in turn may give rise to lower level of anxiety and higher level of self-confidence. Another theoretical reason that can likely explain the link between narcissistic personality trait and pre-exam anxiety and self-confidence is the narcissists' desire to have a highly positive self-evaluation. Formerly, researchers provided strong support for the notion that narcissistic personality was associated with the use of self-enhancement strategies to restore or maintain a favorable self-evaluation. For example, Farwell, and Wohlwend-Lloyd (1998) found that students having higher level of narcissistic personality trait may be more prone to overestimate their final grade. In another study by Robins, and Beer (2001) narcissism has been found to be associated with self-enhancement bias in an academic setting. Moreover, similar results were also obtained in previous studies that support the observed relationship between narcissism, anxiety and self-confidence (Akehurst and Thatcher, 2010; Wallace, Baumeister, and Vohs, 2005).

The result of the present study together with previous ones indicating that narcissistic personality trait may be a psychological construct that can give rise to favorable emotional reactions before an important academic examination should be interpreted with caution. Accordingly, Robins, and Beer (2001) stated that narcissistic personality is not related to academic performance and higher grades. The authors also emphasized that narcissistic individuals' self-enhancement strategies may not be adaptive in long term.

Data did not support the hypothesis that suggests neuroticism should be positively associated with pre-exam anxiety and negatively associated with self-confidence. Similarly, the prediction regarding the association between conscientiousness and pre-exam anxiety and self-confidence was not confirmed. The lack of association of these big five facets to pre-exam anxiety and self-confidence may be explained by the nature of academic examination context. Former studies demonstrating that The Big Five facets may have account for the emotional states or reactions examined this relationship in contexts where performance is determined by largely cognitive skills (Chamorro-Premuzic, Ahmetoglu, and Furnham, 2008). However, in the present study anxiety and self-confidence were measured immediately before a practical exam (archery course final exam) where performance is determined by physical capabilities in addition to emotional and cognitive capabilities. Therefore, in the light of the obtained results, it can be concluded that the context in which academic evaluation is made can moderate the relationship between personality and pre-exam emotional reactions, anxiety and self-confidence in this case.

In future studies researchers should examine this relationship in both practical and theoretical exams. Moreover, researchers should also take into account factors that can possibly mediate the link between personality traits and pre-exam emotional reactions.

\section{REFERENCES}

[1] Akehurst, S., \& Thatcher, J. (2010). Narcissism, social anxiety and self-presentation in exercise. Personality and Individual Differences, 49(2), 130-135. https://doi.org/10.1016/j.paid.2010.03.021

[2] Ames, D. R., Rose, P., \& Anderson, C. P. (2006). The NPI-16 as a short measure of narcissism. Journal of Research in Personality, 40(4), 440-450. https://doi.org/10.1016/j.jrp.2005.03.002

[3] Atay, S. (2009). Narsist KişilikEnvanterinin Türkçe'ye Standardizasyonu. Gazi Üniversitesi İktisadi ve İdari Bilimler Fakültesi Dergisi, 11(1), 181-196.

[4] Cain, N. M., Pincus, A. L., \& Ansell, E. B. (2008). Narcissism at the crossroads: Phenotypic description of pathological narcissism across clinical theory, social/personality psychology, and psychiatric diagnosis. Clinical Psychology Review, 28(4), 638-656. https://doi.org/10.1016/j.cpr.2007.09.006

[5] Chamorro-Premuzic, T., Ahmetoglu, G., \& Furnham, A. (2008). Little more than personality: Dispositional determinants of test anxiety (the Big Five, core self-evaluations, and self-assessed intelligence). Learning and Individual Differences, 18 (2), 258-263. https://doi.org/10.1016/j.lindif.2007.09.002

[6] Chapell, M. S., Benjamin Blanding, Z., Takahashi, M., Silverstein, M. E., Newman, B., Gubi, A., \& McCann, N. (2005). Test anxiety and academic performance in undergraduate and graduate students. Journal of Educational Psychology, 97 (2), 268-274.

https://doi.org/10.1037/0022-0663.97.2.268

[7] Dacanay, A. M. L. (2016). A Model Exploring Cognitive Test Anxiety: Personality and Goal Orientation. BALL STATE UNIVERSITY.

[8] Eysenck, H. J. (1967). The biological basis of personality. Springfield, IL: Thomas.

[9] Eysenck, H. J. (1982). Personality, genetics and behavior. New York: Praeger.

[10] Farwell, L., \& Wohlwend-Lloyd, R. (1998). Narcissistic 
Processes: Optimistic Expectations, Favorable Self-Evaluations, and Self-Enhancing Attributions. Journal of Personality, 66(1), 65-83.

https://doi.org/10.1111/1467-6494.00003

[11] Gabriel, M. T., Critelli, J. W., \& Ee, J. S. (1994). Narcissistic illusions in self-evaluations of intelligence and attractiveness. Journal of Personality, 62(1), 143-155.

[12] Jonkmann, K., Becker, M., Marsh, H. W., Lüdtke, O., \& Trautwein, U. (2012). Personality traits moderate the Big-Fish-Little-Pond Effect of academic self-concept. Learning and Individual Differences, 22(6), 736-746. https://doi.org/10.1016/j.lindif.2012.07.020

[13] Ma, X., \& Xu, J. (2004). The causal ordering of mathematics anxiety and mathematics achievement: A longitudinal panel analysis. Journal of Adolescence, 27(2), 165-179. https://doi.org/10.1016/j.adolescence.2003.11.003

[14] MacIntyre, P. D., \& Gardner, R. C. (1989). Anxiety and secodn langauge learning: toward a theoretical clarification. Langauge Learning, 32, 251-275.

[15] Miller, J. D., Hoffman, B. J., Gaughan, E. T., Gentile, B., Maples, J., \& Keith Campbell, W. (2011). Grandiose and Vulnerable Narcissism: A Nomological Network Analysis. Journal of Personality, 79(5), 1013-1042. https://doi.org/10.1111/j.1467-6494.2010.00711.x

[16] Robins, R. W., \& Beer, J. S. (2001). Positive illusions about the self: Short-term benefits and long-term costs. Journal of Personality and Social Psychology, 80(2), 340-352. https://doi.org/10.1037/0022-3514.80.2.340

[17] Tatar A. (2005). Çok boyutlu kişilik envanteri'nin madde-cevap kuramina göre kisa formunun geliştirilmesi ve psikometrik özelliklerinin incelenmesi. Ege Üniversitesi.

[18] Tok, S., Morali, L. M. (2009). Trait emotional intelligence, the big five personality dimensions and academic success in physical education teacher candidate. Social Behavior and Personality: An International Journal, 37(7), 921-931.

Wallace, H. M., Baumeister, R. F., \& Vohs, K. D. (2005). Audience support and choking under pressure: A home disadvantage? Journal of Sports Sciences, 23(4), 429-438. https://doi.org/10.1080/02640410400021666. 